\title{
PIBID: ANÁLISE DAS TESES E DISSERTAÇÕES NOS PROGRAMAS STRICTO SENSU DE EDUCAÇÃO FÍSICA
}

\author{
Luna Gonçalves dos Reis \\ Universidade Federal do Triângulo Mineiro, Uberaba, Minas Gerais, Brasil. \\ Regina Simoes \\ Universidade Federal do Triângulo Mineiro, Uberaba, Minas Gerais, Brasil.
}

\begin{abstract}
Resumo
O estudo teve como objetivo identificar e analisar as teses e dissertações sobre - Programa Institucional de Bolsa de Incentivo à Docência - PIBID - da área da Educação Física defendidas a partir de 2012 e disponíveis no Catálogo de Teses e Dissertações da Coordenação de Aperfeiçoamento de Pessoal de Nível Superior - CAPES. Foram encontrados, online, 20 trabalhos, alocados em cinco categorias: 1. Formação de Professores; 2. Prática Docente; 3. Políticas Educacionais; 4. Influência na escolha da profissão; e 5. Produção do Conhecimento. O período examinado revelou que apesar de o PIBID ser amplamente discutido, na área da Educação Física, as produções ainda são tímidas e centradas na formação de professores, revelando que há necessidade de se empreender esforços na realização de estudos que contemplem outros aspectos desse programa.
\end{abstract}

Palavras-chave: PIBID. Produção Científica. Bibliometria.

\section{PIBID: ANALYSIS OF THESIS AND DISSERTATIONS IN THE PROGRAMS STRICTO SENSU OF PHYSICAL EDUCATION}

\begin{abstract}
The study had as its main goal to identify and analyze the thesis and dissertations about ProgramaInstitucional de Bolsa de Incentivo à Docência - PIBID in the field of Physical Education which have been defended since 2012 and available on the Catalog of Thesis and Dissertations of "Coordenação de Aperfeiçoamento de Pessoal de Nível Superior - CAPES". It was found 20 works online that are allocated in five categories: 1. Formation of Teachers; 2. Docent Practice; 3. Educational Politics; 4. Influence on the profession's choice; and 5. Knowledge Production. The period examined revealed that, despite PIBID being largely debated, in the field of Physical Education, the productions are still timid and centered on the formation of teachers, revealing that there is a need of putting a lot of efforts on the realization of studies that contemplate other aspects of this program.
\end{abstract}

Keywords: PIBID. Scientific Production. Bibliometrics.

\section{PIBID: ANÁLISIS DE LAS TESIS Y DISERTACIONES EN LOS PROGRAMAS STRIC- TO SENSU DE EDUCACIÓN FÍSICA}

\section{Resumen}

El estudiotuvo como objetivo identificar y analizarlastesis y disertaciones sobre Programa Institucional de Bolsa de Incentivo à Docência - PIBID del área de Educación Física defendi- 
das a partir de 2012 y disponiblesenel Catálogo de Tesis y Disertaciones de la Coordinación de Perfeccionamiento de Personal de Nivel Superior - CAPES. Fueron encontrados, online, 20 trabajos, asignadosen cinco categorías: 1. Formación de profesores; 2. Práctica Docente; 3. Políticas Educativas; 4. Influencia enlaelección de laprofesión; y 5. ProduccióndelConocimiento. El período examinado reveló que a pesar del PIBID ser ampliamente discutido enel área de Educación Física lasproduccionestodavíason tímidas y centradas enlaformación de profesores, revelando que haynecesidad de emprenderesfuerzosenlarealización de estudios que contemplenotros aspectos de este programa.

Palabras clave: PIBID. Producción Científica. Bibliometría

\section{Introdução}

Nos últimos anos, a temática referente à formação de professores tem ocupado um lugar importante no cenário das discussões de Educação Física, sobretudo no meio escolar e na valorização da área de maneira geral, sendo necessário aprofundar as discussões sobre esse campo na realidade brasileira (SAMPAIO; STOUBAUS, 2015). As políticas públicas educacionais exercem um papel fundamental na qualificação da formação docente e na melhoria da qualidade de ensino.

Dentre essas políticas encontra-se o Programa Institucional de Bolsa de Incentivo à Docência (PIBID), desenvolvido pelo Ministério da Educação, com a finalidade de impulsionar estudantes de licenciatura das universidades brasileiras a iniciarem a docência, contribuindo para sua formação e para a melhoria da educação pública (BRASIL, 2008). O programa estabelece uma ligação entre a universidade e a Educação Básica e pressupõe uma integração entre teoria e prática através da inserção de alunos de licenciatura nas escolas públicas, exercendo atividades pedagógicas, com auxílio de bolsas (BRASIL, 2013).

É uma importante iniciativa para formação inicial de professores e uma proposta de incentivo e valorização do magistério, possibilitando aos acadêmicos o contato direto com a realidade escolar (BRAIBANTE; WOLLMANN, 2012), criando uma via de 'mão dupla' entre a teoria e a prática ao propiciar a aproximação entre a formação teórica e as práticas docentes (SOUZA, 2014). Além disso, pretende suprir uma lacuna que incomoda boa parte dos que militam na área da formação de professores: a falta de docentes para atuar em diversos níveis de ensino, em especial no Ensino Médio, tanto que há maior ênfase em atender as licenciaturas das áreas das ciências naturais, da área de letras e posteriormente as demais formações (PANIAGO; SARMENTO, 2017; TANCREDI, 2013).

A participação dos discentes em diálogo com os professores da Escola Básica e da universidade pressupõe a elaboração e o desenvolvimento de projetos colaborativos, indicando que a formação não é estanque e tanto a inicial como a em serviço são importantes e se enriquecem nessa experiência. A realidade da aula é singular, complexa, ambígua e incerta, o que impossibilita que o aluno em processo de formação introduza "receitas" prontas e ou apenas reproduza experiências bem-sucedidas. É preciso que ele vivencie o cotidiano escolar e por meio desta ação crie alternativas com o propósito de garantir a solução de problemas inerentes ao processo de ensino e aprendizagem (OLIVEIRA, 2017; PANIAGO; SARMENTO, 2017).

O futuro docente deve ser preparado para planejar e participar das experiências didático-metodológicas, além de lidar com as situações conflituosas presentes no ambiente escolar e, dessa forma, estar apto para refletir criticamente sobre esses acontecimentos. Para que a formação aconteça de forma condizente com a prática docente, os cursos devem constituir uma ligação direta com a escola, sendo que um dos caminhos é a vivência no PIBID (DARROZ; WANNMACHER, 2015). 
No caso da área da Educação Física, é urgente e necessário repensar esse processo, com vistas a formar profissionais aptos a compreender e contribuir para sociedade na qual estão inseridos, atuando como produtores, transformadores, cocriadores e não apenas reprodutores de saberes (BARBOSA-RINALDI, 2008).

Considerando que muitos estudos foram publicados, com diferentes enfoques de problemas e/ou de experiências exitosas ocorridas ao longo da formação e atuação no programa; o objetivo deste texto é identificar e analisar as teses e dissertações sobre PIBID da área da Educação Física defendidas a partir de 2012 e disponíveis no Catálogo de Teses e Dissertações da Coordenação de Aperfeiçoamento de Pessoal de Nível Superior (CAPES).

\section{Metodologia}

O presente estudo, de caráter bibliográfico denominado "estado da arte" (FERREIRA, 2002), foi realizado online nos cursos de pós-graduação brasileira stricto sensu. Este tipo de investigação possibilita diagnosticar e analisar uma determinada área com vistas a compreender os delineamentos e os desdobramentos de sua produção acadêmico-científica e, apesar dos recortes espaciais e temporais, vislumbrar possibilidades de novas pesquisas (RUFINO et al., 2014; SPOSITO, 2009). O levantamento inicial foi realizado no Catálogo de Teses e Dissertações da CAPES, sendo ano inicial 2012, quando da criação da Plataforma Sucupira, e final 2017.

O primeiro contato como as investigações ocorreu pelos resumos. Foram utilizados como filtro os campos do: título, programa em que o trabalho estava inserido, palavras-chave e o objetivo. Os trabalhos passaram a ser incluídos ou excluídos no banco de dados criado quando abordavam o indicador bibliométrico PIBID, sendo encontrados 523 estudos, dos quais 363 se adequavam à proposta de investigação.

Os 363 trabalhos foram detalhados em uma planilha do Excel a partir das seguintes informações: autor, título, objetivo, área do conhecimento, orientador, programa, nível, lócus da pesquisa, região e participantes. Considerando que o foco era a inserção no âmbito da área da Educação Física, desse montante foram identificadas 20 produções.

Ferreira (2002) realça as limitações de realizar um levantamento de literatura, sobretudo nos moldes do estado da arte, apenas a partir da leitura dos resumos. Sendo assim, é imprescindível ir à fonte com o propósito de conhecer a obra, tomar contato com a pesquisa e garimpar os elementos essenciais para compreender de que forma ela foi desenvolvida ou que métodos foram utilizados para obter os resultados. Para sanar essa lacuna, os trabalhos selecionados foram acessados na íntegra via bibliotecas depositárias para que todo o conteúdo pudesse ser lido, considerando, também que havia resumos que apresentavam dados insuficientes para a compreensão do estudo.

Vencida esta etapa, o material foi agrupado e dividido em três unidades de contexto atendendo aos pressupostos de Moraes (1999) que propõe cinco fases para compor o processo da análise de conteúdo: 1- Preparação das informações: consiste em identificar as diferentes amostras de informação a serem analisadas, através da leitura dos materiais e seleção das que efetivamente estão de acordo com os objetivos da pesquisa; 2- Unitarização: pressupõe reler minuciosamente os materiais para definir a unidade de análise, codificando e isolando cada uma delas para que sejam submetidas à classificação e posteriormente à definição das unidades de contexto; 3- Categorização ou classificação das unidades em categorias: significa agrupar dados a partir de partes comuns existentes entre eles. Pode-se classificar por semelhança ou analogia, conforme critérios previamente estabelecidos ou definidos no processo; 4Descrição: momento de comunicar os significados encontrados nas mensagens analisadas; 5Interpretação: etapa imprescindível da análise de conteúdo, realizada através de fundamenta- 
ção teórica ou com base na produção de teoria a partir dos materiais em análise, atingindo uma compreensão mais aprofundada do conteúdo das mensagens.

Como se trata de um material de acesso livre não houve a submissão do Comitê de Ética em Pesquisa.

\section{O PIBID no contexto das teses e dissertações}

Dentro de um panorama geral, e seguindo os pressupostos de Moraes (1999), os 363 estudos foram divididos em três unidades de contexto, sendo que a maior correspondência se destina à preocupação com questões dos impactos do PIBID para formação de professores, constituição da identidade profissional, as políticas públicas, as repercussões e as contribuições do programa para essa formação. Em seguida aparece a prática docente, que elucida as ações, estratégias e o trabalho pedagógico na prática cotidiana e por último a produção do conhecimento sobre o PIBID, que engloba as produções realizadas no âmbito do programa, como mostra o Quadro 1.

Quadro 1 - Unidades de Contexto das teses e dissertações do Catálogo da CAPES

\begin{tabular}{|c|c|c|c|}
\hline Unidades de Contexto & Teses & Dissertações & Principais Temáticas Envolvidas \\
\hline Formação de Professores & 55 & 260 & $\begin{array}{l}\text { - Impacto do PIBID para formação de profes- } \\
\text { sores } \\
\text { - Contribuições do PIBID para formação de } \\
\text { professores } \\
\text { - Constituição da Identidade profissional } \\
\text { - Políticas Públicas }\end{array}$ \\
\hline Prática docente & 8 & 38 & - Prática Docente \\
\hline $\begin{array}{l}\text { Produção do conhecimento } \\
\text { sobre o PIBID }\end{array}$ & 0 & 2 & - Produções do PIBID \\
\hline TOTAL & 63 & 300 & 363 \\
\hline
\end{tabular}

Fonte: Coleta de dados (2018).

Ao focar especificamente no propósito deste artigo, que é a área da Educação Física, percebe-se que comparativamente com o total, o número de produções é bem menor. A partir da imersão em todos os trabalhos selecionados foi possível detalhar e gerar as seguintes categorias: 1- Formação de Professores; 2- Prática Docente; 3- Políticas Educacionais; 4- Influência na escolha da profissão; e 5- Produção do Conhecimento, como mostra o Quadro 2.

Quadro 2 - Categorias das teses e dissertações da área da Educação Física

\section{FORMAÇÃO DE PROFESSORES}

\begin{tabular}{|c|c|c|}
\hline \multicolumn{3}{|c|}{ DISSERTAÇÕOES } \\
\hline ANO & TÍTULO & AUTOR \\
\hline \multirow[t]{3}{*}{2014} & $\begin{array}{l}\text { O impacto do PIBID-Educação Física na trajetória for- } \\
\text { mativa dos alunos bolsistas e na prática pedagógica de } \\
\text { professores supervisores. }\end{array}$ & Ana Paula Soares de Andrade \\
\hline & $\begin{array}{l}\text { PIBID: Formação continuada para professores de Educa- } \\
\text { ção Física. }\end{array}$ & Cristian Leandro Lopes da Rosa \\
\hline & $\begin{array}{l}\text { Experiências formativas no início da docência mediadas } \\
\text { pelo PIBID Educação Física da Universidade Estadual de } \\
\text { Feira de Santana, Bahia, Vitória - ES. }\end{array}$ & Tatiana Moraes Queiroz de Melo \\
\hline
\end{tabular}




\begin{tabular}{|c|c|c|}
\hline \multirow{4}{*}{2015} & $\begin{array}{l}\text { O PIBID e as aprendizagens na formação inicial de pro- } \\
\text { fessores de EF: uma etnografia com estudantes da FA- } \\
\text { COS/RS. }\end{array}$ & Tiago Nunes Medeiros \\
\hline & $\begin{array}{l}\text { O trabalho pedagógico no PIBD "Cultura Esportiva na } \\
\text { Escola” e suas repercussões para formação inicial em } \\
\text { Educação Física. }\end{array}$ & Daiane Dalla Nora \\
\hline & $\begin{array}{l}\text { O PIBID e a formação docente em Educação Física para } \\
\text { a Educação Infantil. }\end{array}$ & Rodrigo Lema Del Rio Martins \\
\hline & $\begin{array}{l}\text { A formação do professor crítico-reflexivo na Educação } \\
\text { Física: realidades e possibilidades no âmbito do PIBID/ } \\
\text { IFCE }\end{array}$ & Cesar Augusto Sadalla Pinto \\
\hline \multirow[t]{2}{*}{2016} & $\begin{array}{l}\text { O PIBID no processo de formação continuada dos pro- } \\
\text { fessores supervisores de Educação Física: aspectos de } \\
\text { uma política curricular. }\end{array}$ & Gabriel Siqueira Matos \\
\hline & $\begin{array}{l}\text { Experiência formativa do professor supervisor: estudo de } \\
\text { caso do PIBID/Educação Física/UECE }\end{array}$ & Maria Adriana Borges dos Santos \\
\hline \multicolumn{3}{|c|}{ TESES } \\
\hline \multirow[t]{2}{*}{2015} & $\begin{array}{l}\text { O PIBID e a docência na Educação Física: perspectivas } \\
\text { na formação inicial e continuada. }\end{array}$ & Ângela BortoliJahn \\
\hline & $\begin{array}{l}\text { Programa Institucional de Bolsa de Iniciação à Docência } \\
\text { (PIBID) como tempo e espaço de formação: uma análise } \\
\text { do subprojeto PIBID/Educação Física da Universidade } \\
\text { Federal dos Vales do Jequitinhonha e Mucuri (UFVJM). }\end{array}$ & Claudia Mara Niquini \\
\hline \multicolumn{3}{|c|}{ 2. PRÁTICA DOCENTE } \\
\hline \multicolumn{3}{|c|}{ DISSERTAÇÕES } \\
\hline \multirow[t]{2}{*}{2014} & $\begin{array}{l}\text { Meios, estratégias e ações em abordagem interdisciplinar } \\
\text { sobre suplementos alimentares e anabolizantes no ensino } \\
\text { médio }\end{array}$ & Sara Coelho dos Anjos \\
\hline & $\begin{array}{l}\text { A Sistematização do conteúdo jogo nas aulas de Educa- } \\
\text { ção Física do ensino fundamental e médio }\end{array}$ & Dianne Cristina Souza de Sena \\
\hline \multirow{4}{*}{2016} & $\begin{array}{l}\text { A relação memória e corpo na Educação Física: uma } \\
\text { experiência do PIBID-FURB. }\end{array}$ & Luis Carlos Rodrigues \\
\hline & $\begin{array}{l}\text { Proficiência motora de escolares do PIBID em turmas de } \\
\text { anos iniciais }\end{array}$ & Eurico Barcelos dos Santos \\
\hline & $\begin{array}{l}\text { Caracterização das ações realizadas no âmbito de Sub- } \\
\text { projetos } \\
\text { PIBID/CAPES de Educação Física no Rio Grande do Sul }\end{array}$ & Thais Machado Costa \\
\hline & $\begin{array}{l}\text { O trabalho pedagógico das professoras supervisoras do } \\
\text { PIBID: cultura esportiva da escola }\end{array}$ & Jaqueline Welter \\
\hline \multicolumn{3}{|c|}{ 3. POLITICAS EDUCACIONAIS } \\
\hline \multicolumn{3}{|c|}{ DISSERTAÇÃO } \\
\hline 2016 & $\begin{array}{l}\text { Episódios de recontextualização de uma política: o PI- } \\
\text { BID e os subprojetos de Educação Física }\end{array}$ & Milena Engels de Camargo \\
\hline \multicolumn{3}{|c|}{ 4. INFLUÊNCIA NA ESCOLHA DA PROFISSÃO } \\
\hline \multicolumn{3}{|c|}{ DISSERTAÇÃO } \\
\hline 2016 & $\begin{array}{l}\text { A atratividade da carreira docente: uma análise na pers- } \\
\text { pectiva de ex-bolsistas do PIBID do curso de Educação } \\
\text { Física. }\end{array}$ & Sabrina Aparecida de Lima \\
\hline
\end{tabular}




\begin{tabular}{|c|l|c|}
\hline \multicolumn{2}{|c|}{ 5. PRODUÇÃO DO CONHECIMENTO } \\
\hline \multicolumn{2}{|c|}{ DISSERTAÇÃO } \\
\hline $\mathbf{2 0 1 6}$ & $\begin{array}{l}\text { A produção do conhecimento do PIBID Educação Física: } \\
\text { realidade e possibilidades no trato com conhecimento na } \\
\text { formação inicial de professores }\end{array}$ & Cristina Climaco (2016) \\
\hline
\end{tabular}

Fonte: Coleta de dados (2018).

Um aspecto importante na identificação do perfil da produção acadêmica em Educação Física é a localização dos trabalhos por instituições e programas. O Quadro 3 mostra esta questão.

Quadro 3 - Distribuição das teses e dissertações por instituição dos estados da federação

\begin{tabular}{|c|c|c|}
\hline Instituição & Teses & Dissertaç̃̃es \\
\hline UFSM & 0 & 4 \\
\hline FURB, UFC, UFES & 0 & 2 (cada IES) \\
\hline UFGRS & 1 & 1 \\
\hline UFBA & 0 & 0 \\
\hline UFMG & 0 & 1 (cada IES) \\
\hline UFPEL, UFRJ, UFRN, UFTM, UFSJ, UFV & $\mathbf{2}$ & $\mathbf{1 8}$ \\
\hline TOTAL & &
\end{tabular}

Fonte: Coleta de dados (2018).

Observa-se que a região Sul concentra o maior número de trabalhos, provavelmente pelo grande número de instituições e programas na área que estão lotados nos estados da federação desta região.

\section{Formação de Professores}

Dos 11 trabalhos (duas teses e nove dissertações) que têm como foco a formação de professores de Educação Física, consta-se que três trazem questões referentes à formação inicial, três sobre formação continuada e cinco abordam as duas.

No aspecto de formação inicial, o estudo de Medeiros (2015), através da etnografia, descreve o processo de ensino-aprendizagem dos estudantes de um curso de Educação Física do Rio Grande do Sul e os elementos que configuram as aprendizagens construídas no PIBID e como os bolsistas compreendem a contribuição do programa para atuação na Educação Básica. Conclui que há uma relação diferente entre os participantes da pesquisa e as teorias que a embasam, compreendendo ser um desafio transformar a educação e o ensino no país, promovendo uma Educação Física crítica e reflexiva.

Pinto (2015) através do estudo de caso analisa as possíveis contribuições do PIBID para a formação crítico-reflexiva na Educação Física, concluindo que é possível, mas considera indispensável a mudança no tipo de racionalidade que norteia o processo formativo e a prática docente na área, uma vez que esta formação deve ancorar-se em uma perspectiva históricocrítica de mundo, do ser humano e de pedagogia. 
O estudo de Dalla Nora (2015), pelo viés da pesquisa documental e entrevista semiestruturada com acadêmicos que participaram do processo, constatou que o trabalho pedagógico no subprojeto de Educação Física promoveu a aproximação da realidade escolar e trocas de experiência, contribuindo para formação inicial de seus participantes.

A temática formação continuada de professores foi evidenciada no trabalho de Rosa (2014),que investigou através da pesquisa documental e entrevista semiestruturada, se a organização e a participação dos professores de Educação Física nos subprojetos PIBID da Universidade Federal de Santa Maria (UFSM) e da Universidade Federal do Pampa (UNIPAMPA) se constitui, para os professores supervisores, em uma formação continuada. Os resultados mostram que apesar de um dos entrevistados não compreender esse espaço como tal, a maioria percebeu que as diferentes ações desenvolvidas, ao longo desse período no PIBID, contribuíram para a formação.

Santos (2016a), a partir do estudo de caso, analisou o processo de formação continuada do Professor Supervisor (PS) em sua experiência formativa no PIBID/Educação Física/UECE, concluindo que esse favorece e valoriza a formação continuada, o exercício da prática da reflexão, promove a aproximação entre a escola e a universidade e aperfeiçoa a prática pedagógica. Da mesma forma, Matos (2016) analisou o papel do PIBID no desenvolvimento da formação continuada dos professores supervisores de Educação Física em uma perspectiva de formação profissional e de ressignificação do currículo em um trabalho de campo, concluindo que as características do programa atuam como uma política para atingir o foco de muitos problemas que vêm de desenhando historicamente na educação e apresentando-se como potencialmente importante para ser um braço das políticas de formação continuada do governo.

No que tange tanto a formação inicial como a continuada, Andrade (2014) analisou o impacto do PIBID na formação inicial dos licenciandos de Educação Física e na prática pedagógica dos professores supervisores do subprojeto da área da Universidade Federal do Piauí (UFPI). Os resultados mostraram que o programa produziu resultados positivos para ambos. Para os bolsistas foi uma oportunidade de compreender o papel do professor e da relação entre professor e aluno, além de experienciara docência nos espaços reais da profissão em diferentes realidades educacionais e para os supervisores possibilitou transformações impactantes e positivas na prática pedagógica.

Martins (2015) analisou os processos formativos empreendidos pelo PIBID, bem como as práticas pedagógicas de bolsistas de iniciação à docência e do professor supervisor em um Centro Municipal de Educação Infantil de Vitória/ES. A partir da observação participante, concluiu que o programa elucida uma formação dialogada entre os pressupostos do programa e as práticas existentes no cotidiano escolar, uma vez que a imersão dos licenciandos na escola possibilita um avanço na formação de professores e ao mesmo tempo contribui para revitalização da profissão docente.

Os estudos de Melo (2015) e Niquini (2015) destacam o reconhecimento do PIBID como um programa que aproxima a universidade da escola, além de proporcionar a qualificação da formação para Educação Básica, revitalizando as práticas da/e na escola e valorizando a ação do professor, além de funcionar como uma experiência formativa que intensifica o desenvolvimento profissional do docente e potencializa tanto a formação inicial quanto a continuada.

Jhan (2015), ao investigar as contribuições do PIBID no processo formativo docente em Educação Física, esclareceu que o programa busca fomentar a pesquisa e estimular os acadêmicos bolsistas a serem pesquisadores, bem como os incentiva também a refletirem sobre a relevância social das pesquisas na área da educação e a pensarem nos problemas do cotidia- 
no escolar. Além disso, aponta ser uma oportunidade para que a ação-reflexão-ação se torne parte do cotidiano do professor.

É evidente a preocupação com a formação de professores, tanto no quadro geral quanto no específico e sobre isso, Nóvoa (2009) diz que a formação deve contribuir para promover, nos futuros professores, hábitos essenciais de uma profissão como reflexão e autorreflexão. Em tese, a formação inicial está fundamentada num discurso didático baseado em modelos de aluno, de professor e de escola idealizados e inadequados para enfrentar as situações reais de ensino/aprendizagem que se constituem em condições sociais complexas (MOLINA NETO; MOLINA, 2002).

Assim, como na maioria dos trabalhos sobre o PIBID, também na área da Educação Física, a maior correspondência das produções está relacionada à Formação de Professores, uma vez que essa temática é fundamental para uma educação de qualidade. Porém, formar profissionais capazes de atuar no cotidiano escolar em constante transformação é um desafio que se apresenta (BRAIBANTE; WOLLMAN, 2012). Nessa lógica, o PIBID se constitui como uma importante ferramenta que visa refletir sobre o que acontece na escola, valorizar a docência e delinear novos rumos para educação brasileira.

Enquanto programa de incentivo à iniciação à docência, o PIBID insere-se no contexto da Educação Básica como importante política pública, além de contribuir e influenciar a qualificação dos professores da Educação Básica, das universidades e também dos licenciandos, provocando um impacto significativo nos cursos de licenciatura (NEITZEL; FERREIRA; COSTA, 2013).

Para Mattana et al. (2014), a contribuição do PIBID vai além do enriquecimento intelectual dos alunos, tendo em vista a relação mútua estabelecida entre bolsistas, alunos e professores por intermédio do programa. Ao colocar os graduandos em contato com a pluralidade do ambiente escolar, o programa possibilita refletir sobre o processo educativo, tornando-se uma alternativa para o fortalecimento das licenciaturas e aliado fundamental na formação de novos professores.

Formar professores requer compreender aspectos muito amplos, que vão além de discutir políticas públicas para Educação Básica ou qual o papel do professor no contexto atual da educação no Brasil. É necessário e urgente promover reflexões e debates no que se refere às especificidades do campo de atuação e sobre a atratividade e valorização da profissão docente.

\section{Prática Docente}

Nessa temática encontram-se os trabalhos relacionados aos saberes, ações, atividades e estratégias didáticas desenvolvidas no PIBID. Sena (2014) apresenta e discute uma proposta de sistematização do conteúdo jogo nas aulas de Educação Física do Ensino Fundamental e Médio, a partir da pesquisa-ação com a participação de estudantes PIBID da Universidade Federal do Rio Grande do Norte (UFRN), professores supervisores atuantes e escolares. Essa proposta possibilitou um redimensionamento das práticas dos professores e o programa influenciou no processo de transformação dessa ação, refletindo em atividades que manifestaram uma forma de trabalhar de forma progressiva, reflexiva, discursiva e significativa para a disciplina.

Dos Anjos (2014) investigou os meios e ações desenvolvidas por ex-bolsistas da Universidade Federal de São João Del-Rei (UFSJ) em subprojetos do PIBID/CAPES/MEC, em uma abordagem interdisciplinar no interior da terceira série do Ensino Médio. Os bolsistas desenvolveram um projeto interdisciplinar, entre as disciplinas Química e Educação Física, mantendo relações com o tema saúde. Foi possível perceber que várias forças coordenaram o 
trabalho interdisciplinar como: a tarefa, o texto, o tema e os meios e deram forma às ações dos bolsistas, caracterizando a interdisciplinaridade como estrutural, na qual as disciplinas já começavam no mesmo grau de importância, com trocas recíprocas, o enriquecimento mútuo e a colocação de conteúdos e métodos em comum. Rodrigues (2016) trata da relação entre memória e corpo nas práticas pedagógicas do PIBID da Universidade Regional de Blumenau (FURB) de Educação Física. Os resultados da pesquisa de campo apontaram para um programa que valoriza a formação docente no que se refere a uma experimentação do que acontece no cotidiano da escola.

Santos (2016b) analisou a eficiência do programa fundamentado no Jogo Orientado em aulas de Educação Física para escolares, inferindo que a introdução de um programa dessa natureza, através de métodos qualificados, é capaz de produzir repostas significativas nos aspectos motores e na proficiência motora.

Costa (2016) estabeleceu possíveis relações das ações realizadas em subprojetos PIBID/CAPES da área curricular de Educação Física (EF) no estado do Rio Grande do Sul (RS) com as desenvolvidas nas Instituições de Ensinos Superiores (IES) e nas Escolas e Educação Básica (EEB), concluindo que as ações coordenadas pelos subprojetos estudados, potencializaram a formação inicial, indo ao encontro das experiências de aprendizagem. Porém, a autora considera que essas ações ainda estão distantes dos cursos de licenciatura, entendendo como um aspecto responsável por desviar a melhoria da qualidade da Educação Básica.

Welter (2016) analisou as repercussões do PIBID no trabalho pedagógico das professoras supervisoras e evidenciou que houve contribuições para formação continuada, relação entre escola e universidade, o incentivo à produção do conhecimento, trabalho coletivo e aproximação entre teoria e prática.

Segundo Silva, Braúna e Ferenc (2015), o saber dos professores é formado a partir de vários saberes que constituem a prática docente, sendo uma consequência da relação estabelecida entre os conhecimentos adquiridos ao longo da sua trajetória profissional, familiar e escolar. Diante disso, o PIBID funciona como uma ponte que ligaa escola e a universidade, estreitando os laços entre as instituições, promovendo a oportunidade de vivenciar as experiências da sala de aula e do contexto da escola de maneira geral que podem ser traduzidos em saberes.

A experiência do exercício da profissão pode funcionar como uma fonte privilegiada de saberes, que englobam os conhecimentos, as habilidades e as atitudes dos docentes (TARDIFF, 2002). Clates e Güinther (2015) consideram as experiências formadoras vivenciadas no PIBID, como importantes contribuições para a formação dos egressos, pois, as práticas pedagógicas desenvolvidas auxiliam nas experiências curriculares e complementam a graduação, além disso, são capazes de influenciar a visão dos bolsistas e dos professores ao longo do programa.

\section{Políticas Educacionais}

O trabalho de Camargo (2016) analisa a política PIBID e seus processos de recontextualização junto aos subprojetos de Educação Física, em três IES do estado de Santa Catarina, utilizando o método de pesquisa a Abordagem do Ciclo de Políticas (ACP), proposta por Ball (1994) e como fonte de análise o Projeto Institucional, Subprojeto de Educação Física e Relatório Anual de Atividades. Diante da análise dos dados, verificou-se que esses documentos permitem a construção de novos textos e discursos e, assim, garantem a singularidade dos espaços e das pessoas, desenhando-se uma outra Educação Física, com o foco na cultura corporal do movimento, que se relaciona com as tecnologias que inova, que reconhece o momento atual e as diferentes formas de construção das subjetividades. 
Felício (2014) destaca o PIBID como uma das políticas públicas mais significativas nos últimos anos, em âmbito nacional. Já Brito (2017) considera o programa como uma política de educação nacional que vem trilhando novos caminhos para uma política de formação de professores, através da problematização e da compreensão das demandas que o cenário educacional apresenta, apostando na construção de uma identidade de professor e constituição de saberes fundamentados na interação entre a universidade e a escola.

\section{Influência do PIBID na escolha da profissão}

Lima (2016) aborda a influência do PIBID na escolha da profissão. O estudo buscou caracterizar o perfil dos ex-bolsistas, investigar o local de atuação e identificar as razões para decisão de permanecer ou não no magistério nas escolas públicas. A análise dos dados da pesquisa indica que a maioria dos sujeitos entrevistados considera a experiência do PIBID significativa e destacam como maiores contribuições do programa: a inserção na realidade escolar, o planejamento e trato com os conteúdos não vistos na graduação. Porém, os dados encontrados apontam que a intenção de atuar na escola pública não se concretizou na prática e os ex-bolsistas destacaram a falta de reconhecimento do papel da Educação Física escolar e a desvalorização do docente como as maiores dificuldades no exercício do magistério, além disso, ressalta-se que as condições de trabalho precárias comprometem a prática pedagógica.

No que se refere à desvalorização do docente, Pereira e Oliveira (2016) ressaltam que a valorização da profissão docente não se reduz ao reconhecimento da sociedade, uma vez que também está subordinada à necessidade de seterclareza nas ações que são destinadas àprofissão. A atratividade da carreira docente, no que diz respeito a salários e condições justas de trabalho, e também na assunção e reconhecimento do professor com relação a sua profissão devem ser considerados.

Para Gatti (2009), a escolha de uma profissão, bem como a inserção no mundo do trabalho, é cada vez mais um dilema, uma vez que essa escolha não se relaciona apenas às características pessoais, mas também ao contexto político, econômico, cultural e social no qual o sujeito está inserido. Por outro lado, a investigação de Oliveira, Ribeiro e Afonso (2018) destaca a satisfação de 20 professores de Educação Física da rede federal do Sul do país com o exercício da sua profissão, pois o trabalho pedagógico está relacionado ainda com a troca entre alunos, o reconhecimento por parte deles e a realização profissional.

\section{Produção do conhecimento no PIBID}

Climaco (2016) apresentou um balanço da produção do PIBID Educação Física no Brasil sobre o trato com os conhecimentos específicos da cultura corporal, fundamentada nos trabalhos do CONBRACE - GTT5 - Escola no período 2011-2015. Os dados produzidos possibilitaram a compreensão do PIBID como imprescindível na concretização dos saberes e motivação para escrever artigos a partir da observação e reflexão de suas aulas e dos conhecimentos adquiridos através das vivências no âmbito do programa.

O PIBID tem demonstrado resultados que apresentam perspectivas de qualificação do ensino a médio e longo prazo, além formar profissionais conscientes na realidade em que irão atuar, capazes de produzir conhecimento, bem como investigar e refletir sobre sua prática profissional. A aproximação com o campo de atuação proporciona ao licenciando a oportunidade de vivenciar o chão da escola, bem como suas dificuldades e desafios, provendo a constituição de uma identidade profissional fundamentada na mediação entre a teoria e a prática (RAUSCH; FRANTZ, 2013). 
Ao relacionar o levantamento inicial realizado com a área da Educação Física, encontramos uma situação similar referente à correspondência de produções para cada categoria. Mas, ao mesmo tempo, é possível perceber a pequena quantidade de produções, comparandose ao número de publicações de maneira geral.

\section{Conclusão}

As pesquisas apresentadas evidenciam a contribuição do PIBID para formação de professores da escola e da universidade, diminuindo a distância entre a teoria e a prática. Demonstram perspectivas de qualificação do ensino a médio e longo prazo, formando profissionais conscientes na realidade em que atuarão,capazes de produzir conhecimento, bem como investigar e refletir sobre sua prática profissional, apesar do número reduzido de estudos quando se trata da área da Educação Física.

Houve, em todo o levantamento, maior preocupação com a formação de professores e menor atenção à prática pedagógica. Carecendo, então, de maiores investimentos no chão da escola e ou no processo de inserção dos ex-bolsistas na Educação Básica, visando contribuir e problematizar as discussões já existentes e fundamentar e subsidiar novos debates no contexto da Educação Brasileira.

\section{Referências}

ANDRADE, Ana Paula Soares de. O impacto do PIBID-Educação Física na trajetória formativa dos alunos bolsistas e na prática pedagógica de professores supervisores Uberaba - MG. 2014. 152 f. Dissertação (Mestrado em Educação Física) - Universidade Federal do Triângulo Mineiro, Uberaba, 2014.

BARBOSA-RINALDI, Ieda Parra. Formação inicial em Educação Física: uma nova epistemologia da prática docente. Movimento, Porto Alegre, v. 14, n. 03, p. 185-207, 2008.

BRAIBANTE, Maria Elisa Fortes; WOLLMANN, Ediane Machado. A influência do PIBID na formação dos acadêmicos de Química licenciatura da UFSM. Química Nova na Escola, São Paulo, v. 34, n.4, p. 167-172, 2012.

BRASIL. Ministério da Educação. Coordenação de Aperfeiçoamento de Pessoal de Nível Superior - CAPES. Diretoria de Formação de Professores da Educação Básica DEB. Relatório de Gestão PIBID. Brasília: CAPES, 2013. Disponível em: http://www.capes.gov.br/educacao-basica/capespibid/pibid. Acesso em: 28 mar. 2018.

BRASIL, CAPES. Programa Institucional de Bolsa de Iniciação à Docência, 2008. Disponível em: http://www.capes.gov.br/educacao-basica/capespibid/pibid. Acesso em: 28 mar. 2018.

BRITO, Robson Figueiredo. Políticas públicas de educação: o PIBID uma forma de fazer o direito à educação acontecer. VirtuaJus, Belo Horizonte, v.13, n.1, p.145-162. 2017.

CAMARGO, Milena Engels de. Episódios de recontextualização de uma política: o pibid e os subprojetos de Educação Física. 2016. 85 f. Dissertação (Mestrado em Educação) - 
Universidade Regional de Blumenau, Centro de Ciências da Educação, Artes e Letras, Blumenau, 2016.

CLATES, Daniela de Moura; GÜNTHER Maria Cecília Camargo. O PIBID e o percurso formativo de professores de Educação Física. Motrivivência, Florianópolis, v. 27, n. 46, p. 53-68, 2015.

CLIMACO, Josiane Cristina. A produção do conhecimento do PIBID Educação Física: realidade e possibilidades no trato com conhecimento na formação inicial de professores. 2016. 100 f. Dissertação (Mestrado em Educação) - Universidade Federal da Bahia, Bahia, 2016.

COSTA, Thais Machado. Caracterização das ações realizadas no âmbito de subprojetos PIBID/CAPES de Educação Física no Rio Grande do Sul. 2015. 141 f. Dissertação (Mestrado em Educação) -Universidade Federal de Santa Maria, Centro de Educação, Santa Maria, 2015 .

DALLA NORA, Daiane. O trabalho pedagógico no PIBID - "Cultura esportiva na escola" e suas repercussões para a formação inicial em Educação Física. 2015. 117 f. Dissertação (Mestrado em Educação Física) - Universidade Federal de Santa Maria, Centro de Educação Física, Santa Maria, 2015.

DARROZ, Luiz Marcelo; WANNMACHER, Clóvis Milton Duval. Aprendizagem docente no âmbito do PIBID/Física: a visão dos bolsistas de iniciação à docência. Ensaio Pesquisa em Educação em Ciência, Belo Horizonte, v. 17, n.3, p.727-748, 2015.

DOS ANJOSSara Coelho. Processos socioeducativos e práticas escolares meios, estratégias e ações em abordagem interdisciplinar sobre suplementos alimentares e anabolizantes no ensino médio. 2014. 142 f. Dissertação (Mestrado em Educação) Universidade Federal de São João Del-Rei, São João Del-Rei, 2014.

FELÍCIO, Helena Maria dos Santos. O PIBID como "terceiro espaço" de formação inicial de professores. Revista Diálogo Educacional, Curitiba, v. 14, n. 42, p. 415-434, 2014.

FERREIRA, N. S. de A. As pesquisas denominadas “estado da arte". Educação \& sociedade, Campinas, v. 23, n. 79, p. 257-272, 2002.

GATTI, Bernardete A. Atratividade da carreira docente no Brasil: relatório preliminar. São Paulo: Fundação Victor Civita, 2009.

JAHN, Ângela Bortoli . O PIBID e a docência na Educação Física: perspectivas na formação inicial e continuada. 2015.135 f. Tese (Doutorado em Educação em Ciências: Química da Vida e Saúde) - Universidade Federal do Rio Grande do Sul, Instituto de Ciências Básicas da Saúde, Porto Alegre, 2015.

LIMA,Sabrina Aparecida de. A atratividade da carreira docente: uma análise na perspectiva de ex-bolsistas do PIBID do curso de Educação Física. 2016. 205 f. Dissertação (Mestrado em Educação) -Universidade Federal de Viçosa, Centro de Ciências Humanas, Departamento de Educação, Viçosa, 2016. 
MARTINS, Rodrigo Lema Del Rio. O PIBID e a formação docente em Educação Física para a educação infantil. 2015.167 f. Dissertação (Mestrado em Educação Física) - Universidade Federal do Espírito Santo, Centro de Educação Física e Desportos, Vitória, 2015.

MATOS, Gabriel Siqueira. O PIBID no processo de formação continuada dos professores supervisores de Educação Física: aspectos de uma política curricular. 2016. 103 f. Dissertação (Mestrado em Educação) - Universidade Federal do Rio de Janeiro, Centro de Filosofia e Ciências Humanas, Rio de Janeiro, 2016.

MATTANA, Stéfani Dutra; ZANOVELLO, Regiane; THEISEN, Geovane Rafael; MORESCO, Terimar Ruoso; GARLET, Tânea Maria Bisognin. Contribuições do PIBID na formação inicial: intersecções com os pontos de vista de licenciandos de Biologia. Revista Eletrônica em Gestão, Educação e Tecnologia Ambiental, Santa Maria, v. 18 n. 3, p.1059-1071, 2014.

MEDEIROS, Tiago Nunes. O PIBID e as aprendizagens na formação inicial de professores de Educação Física: uma etnografia com estudantes da FACOS/RS. 2015. 210 f. Dissertação (Mestrado em Ciências do Movimento Humano) - Universidade Federal do Rio Grande do Sul, Escola de Educação Física, Porto Alegre, 2015.

MELO, Tatiana Moraes Queiroz. Experiências formativas no início da docência mediadas pelo PIBID Educação Física da Universidade Estadual de Feira de Santana. 2015. 185 f. Dissertação (Mestrado em Educação) - Universidade Federal do Espírito Santo, Centro de Educação, Vitória, 2015.

MOLINA NETO, Vicente; MOLINA, Rosane Kreusburg. Capacidade de escuta: questões para a formação docente em Educação Física. Movimento, Porto Alegre, v. 8, n. 1, p. 57-66, jan./abr. 2002.

MORAES, Roque. Análise de conteúdo. Revista Educação. São Paulo, v. 22, n. 37, p. 7-32, 1999.

NEITZEL, Adair de Aguiar; FERREIRA, Valéria Silva; COSTA, Denise. Os impactos do PIBID nas licenciaturas e na Educação Básica. Conjectura: Filosofia da Educação, Caxias do Sul, v. 18, n. especial, p. 98-121, 2013.

NIQUINI, Cláudia Mara. Programa Institucional de Bolsa de Iniciação à Docência (PIBID) como tempo e espaço de formação: uma análise do subprojeto PIBID/Educação Física da Universidade Federal dos Vales do Jequitinhonha e Mucuri (UFVJM). 2015. 257 f. Tese (Doutorado em Educação) - Universidade Federal de Minas Gerais, Faculdade de Educação, Belo Horizonte, 2015.

NÓVOA, António. Para una formación de profesores construida dentro de la profesión. Revista de Educación, Madrid, n. 350, p. 203-218, 2009.

OLIVEIRA, Hélvio Frank. A bagagem do PIBID para a formação inicial docente e para a construção da identidade profissional. Trabalhos em Linguistica Aplicada, Campinas, v.56, n.3, p.913-934, 2017. 
OLIVEIRA, Ivan Bremm de; RIBEIRO, José Antonio Bicca; AFONSO, Mariangela da Rosa. Satisfação com a profissão: um estudo com professores de Educação Física. Pensar a Prática, Goiânia, v. 21, n. 1, p. 82-95, 2018.

PANIAGO, Rosenilde Nogueira; SARMENTO, Teresa. A Formação na e para a pesquisa no PIBID: possibilidades e fragilidades. Educação \& Realidade, Porto Alegre, v. 42, n.2, p.771$792,2017$.

PEREIRA, Sueli Meneze; OLIVEIRA, Valeska Maria Fortes. Valorização do magistério da educação básica: entre o legal e o real. Formação Docente, Belo Horizonte, v. 08, n. 14, p. 33-48, 2016

PINTO, Cesar Augusto Sadalla. A formação do professor crítico-reflexivo na Educação Física: possibilidades no âmbito do PIBID. 2015. 191 f. Dissertação (Mestrado em Educação) - Universidade Estadual do Ceará, Centro de Educação, Fortaleza, 2015.

RAUSCH, Rita Buzzi; FRANTZ, Matheus Jurgen. Contribuições do PIBID à formação inicial de professores na compreensão de licenciandos bolsistas. Atos de Pesquisa em Educação, Blumenau, v. 8, n. 2, p.620-641, 2013.

RODRIGUES, Luís Carlos. A relação memória e corpo na Educação Física: uma experiência do PIBID-FURB. 2016. 116 f. Dissertação (Mestrado em Educação) - Universidade Regional de Blumenau, Centro de Ciências da Educação, Blumenau, 2016.

ROSA, Cristian Leandro Lopes da. PIBID: formação continuada para professores de Educação Física. 2014. 114 f. Dissertação (Mestrado em Educação Física) - Universidade Federal de Pelotas, Pelotas, 2014.

RUFINO, Luis Gustavo Bonatto; FERREIRA, Aline Fernanda; CARVALHO, Amarílis Oliveira; RICCI, Christiano Streb; DARIDO, Suraya Cristina. Educação Física escolar no ensino médio: analisando o estado da arte. Revista Brasileira de Ciências do Esporte, Florianópolis, v. 36 p.353-369, 2014.

SAMPAIO, Adelar Aparecido; STOBÄUS, Claus Dieter. Mal/bem-estar na formação inicial docente: perspectivas em contextos de mudanças. Perspectivas em Diálogo: Revista de Educação e Sociedade, Naviraí, v. 3, n.5, p.143-160, 2016.

SANTOS, Maria Adriana Borges dos. Experiência formativa do professor supervisor: estudo de caso do PIBID/Educação Física/UECE. 2016. 167 f. Dissertação (Mestrado em Educação) - Universidade Estadual do Ceará, Centro de Educação, Fortaleza, Ceará, $2016 \mathrm{a}$.

SANTOS, Eurico Barcelos dos. Proficiência motora de escolares do PIBID em turmas de anos iniciais. 2016. 91 f. Dissertação (Mestrado em Educação Física) - Universidade Federal de Santa Maria, Santa Maria, 2016b.

SENA, Dianne Cristina Souza de. A sistematização do conteúdo jogo nas aulas de Educação Física do ensino fundamental e médio. 2014. $261 \mathrm{f}$. Dissertação (Mestrado em Educação) - Universidade Federal do Rio Grande do Norte. Centro de Educação - Natal, 2014. 
SILVA, Tatianne Ferreira; BRAÚNA, Rita de Cássia Alcântara; FERENC, Alvaniza Valente Fernandes. O PIBID de química: identificando ações e saberes na formação de licenciandos. Educação em Perspectiva, Viçosa, v. 6, n. 1, p. 142-162, 2015.

SOUZA, Roger Marchesini de Quadros. O Programa institucional de bolsas de iniciação à docência numa universidade da grande São Paulo: depoimentos, contradições e reflexões preliminares. Acta Scientiarum Education, Maringá, v. 36, n. 2, p. 309-316, 2014.

SPÓSITO, Marilia Pontes. O estado da arte sobre juventude na pós-graduação brasileira: educação, ciências sociais e serviço social (1999-2006). Belo Horizonte: Argumentum, 2009.

TANCREDI, Regina Maria Simões Puccinelli. Políticas públicas de formação de professores: o PIBID em foco. Revista Exitus, Santarém, v. 03, n.01, p. 13-31 2013.

TARDIF, Maurice. Saberes docentes e formação profissional. Petrópolis, RJ: Vozes, 2002

WELTER, Jaqueline. $O$ trabalho pedagógico das professoras supervisoras do PIBID: cultura esportiva da escola. 2016. 159 f. Dissertação (Mestrado em Educação Física) - Universidade Federal de Santa Maria, Santa Maria, 2016.

Recebido em: 18/03/2018

Revisado em: 01/04/2019

Aprovado em: 01/04/2019

Endereço para correspondência:

lunareis449@gmail.com

Luna Gonçalves dos Reis

Universidade Federal do Triângulo Mineiro,

Departamento de Ciências do Esporte.

Av. Getulio Guaritá, 159

Abadia

38025440 - Uberaba, MG - Brasil. 